\title{
SEJARAH SINGKAT KERAJAAN CIREBON
}

\author{
A Brief History of The Kingdom of Cirebon
}

\author{
Oleh Heru Erwantoro \\ Balai Pelestarian Sejarah dan Nilai Tradisional Bandung \\ Jln. Cinambo No. 136 Ujungberung Bandung \\ Email: haninafina@gmail.com
}

\begin{abstract}
Abstrak
Adanya kecenderungan beberapa daerah yang dahulunya merupakan pusat kerajaan untuk membentuk provinsi sendiri merupakan fenomena yang muncul di era reformasi. Di Jawa Barat, setelah Banten memisahkan diri dari Provinsi Jawa Barat dan membentuk Provinsi Banten, kini giliran Cirebon berkeinginan juga untuk memisahkan diri dan membentuk provinsi tersendiri. Adanya fenomena untuk memisahkan diri itu tentu saja menimbulkan pertanyaan, ada apa dengan wilayah-wilayah yang dahulunya pernah menjadi pusat kerajaan? Berbagai persoalan masa kini sesungguhnya dapat dimengerti dan dicarikan solusinya melalui pendekatan ilmu sejarah. Begitu juga dengan fenomena keinginan Cirebon untuk membentuk provinsi sendiri. Dari penelusuran sejarah dapatlah dikatakan bahwa momentum reformasi dan otonomi daerah mendorong para elit Cirebon bernostalgia dengan masa lalu. Romantisme akan masa keemasan Kerajaan Cirebon menjadi model ideal untuk membangun wilayah Cirebon dan sekitarnya di masa yang akan datang. Memang pada masa keemasan Kerajaan Cirebon, Cirebon mengalami perkembangan yang pesat dalam segala bidang kehidupan.
\end{abstract}

Kata kunci: zaman keemasan, Cirebon, otonomi, provinsi.

\begin{abstract}
After reformation, some regions that were previously kingdoms claimed their status for province. First, Banten in the Province of West Java has succeeded in doing it and Cirebon is following to do the same. This is very interesting: claim for separation emerged from regions that were previously great, independent kingdoms. What is really happening? The author conducted history method to seek solution for this problem. The result shows that the elites of Cirebon court want to revive old glory of their kingdom when it experieced many great achievements in almost every areas of life. Those glorious time become model for them to build future Cirebon. This romanticism has been driven by political situation, especially reformation and regional autonomy.
\end{abstract}

Keywords: golden age, Cirebon, autonomy, province. 


\section{A. PENDAHULUAN}

Sejalan dengan semangat reformasi, Keraton Kasepuhan Cirebon menjadi pusat "penggodokan ide pembentukan Provinsi Cirebon". Era reformasi yang ditindaklanjuti oleh otonomi daerah rupanya yang menjadi pendorong utama munculnya gagasan pembentukan Propinsi Cirebon. Otonomi daerah memacu para elit politik lokal untuk memacu pembangunan daerahnya. Pangeran Raja Adipati Arief Natanegara, putra mahkota Kasepuhan mengatakan:

Banyak alasan di balik keinginan pembentukan Provinsi Cirebon ini. Selain secara sejarah Cirebon merupakan daerah otonom, wilayah ini punya potensi ekonomi tinggi. Kekayaan alam yang paling besar adalah cadangan minyak yang tersebar di sepanjang pantai Indramayu dan Cirebon. Sebagai kota pelabuhan, Cirebon juga jadi pintu gerbang arus perdagangan sangat penting. Setiap bulan, sekitar 1.600 kontainer keluar untuk tujuan ekspor. Potensi ini belum digarap maksimal, Pemerintah Provinsi Jawa Barat seakan tak serius menyentuh Cirebon. Denyut pembangunan lebih banyak terpusat di Bandung, kami kebagian apa? Sehingga daerah yang mempunyai kekayaan yang melipah hanya jadi kantong kemiskinan (Gatra, 2 Desember 2002).

Di Jawa Barat, upaya pemisahan diri untuk membentuk provinsi baru sebelumnya telah dilakukan oleh elit Banten. Apakah niat elit Cirebon untuk membentuk Provinsi Cirebon itu terinspirasi oleh elit Banten? Atau memang ada kecenderungan daerahdaerah yang dahulunya bekas pusat kerajaan, ingin berdiri secara otonom? Mengapa ada kerinduan dan romantisme pada kerajaan?

Menurut Azyumardi Azra, munculnya kerinduan pada kerajaan atau kesultanan dalam masyarakat daerah di Indonesia disebabkan oleh dua hal. Pertama, adanya kemerosotan kepercayaan yang terus berlanjut pada indentitas dan kepemimpinan sentralistik dan monopolitik. Kedua, otono- misasi dan desentralisasi, yang menemukan momentum, justifikasi, dan legalitasnya dalam era reformasi ini, pada pihak lain menghendaki daerah memiliki indentitasnya sendiri (Gatra, 2 Desember 2002).

Pada konteks itulah, munculnya kerinduan dan romantisme pada kerajaan atau kesultanan dapat dipahami. Dalam kerinduan dan romantisme itu, kerajaan tidak hanya dianggap sebagai entitas politik, indentitas daerah, dan suku bangsa di masa lalu, akan tetapi juga dibayangkan dapat memberikan alternatif kepemimpinan di masa kini dan masa datang. Dengan demikian, kerajaan dapat dijadikan identitas yang memiliki landasan sosio-historis yang kuat sehingga viable untuk masa kini dan mendatang.

Lebih jauh ditegaskan oleh Azyumardi Azra bahwa kasus-kasus tertentu, indentitas kerajaan di masa silam sebagian besar memang tumpang tindih dengan etnisitas dan batas-batas wilayah provinsi. Provinsi Banten hampir identik dengan etnisitas dan Kesultanan Banten; gagasan pembentukan Provinsi Cirebon memiliki landasan historisnya pada Kesultanan Cirebon. Begitulah gagasan pembentukan Provinsi Cirebon mengisyaratkan proses indentifikasi Provinsi Cirebon dengan Kerajaan Cirebon, terbukti selain menjadi pusat penggodokan ide pembentukan Provinsi Cirebon, juga dari wilayah yang akan dimasukkan ke dalam Provinsi Cirebon adalah daerah-daerah yang dahulunya termasuk ke dalam wilayah Kerajaan Cirebon, seperti Kabupaten dan Kota Cirebon, Kabupaten Indramayu, Kabupaten Kuningan, dan Majalengka.

Kerinduan dan romantisme pada Kerajaan Cirebon mengisyaratkan bahwa "ada sesuatu atau banyak hal pada masa Kerajaan Cirebon yang dianggap baik" sehingga kebaikan itu bila dilakukan lagi akan dapat membantu mengatasi berbagai persoalan yang dialami pada masa kini. Kecenderungan seperti itu bukanlah dorongan yang bersifat emosional, tetapi sesuai dengan apa yang dikatakan oleh pakar sejarah dari Filipina, JRM Taylor berikut ini: 
Para ahli sejarah sering memberi nasihat peringatan, yaitu untuk mau melihat sejarah. Setelah melihat masa lampau akan nampak bahwa pengertian dan pemahaman kita tentang masa kini sebenarnya miskin. Berbagai aspek sejarah tersembunyi dari pandangan kita. Ini bisa bersumber dari atau dipertajam oleh proses misedukasi. Karena tidak mempunyai akses yang cukup terhadap fakta atau kebenaran sejarah, maka suatu sense of historis makin menipis (M. Dawam Rahardjo dalam Prisma, 8 Agustus 1983, hal. 2).

Dengan demikian, kerinduan dan romantisme itu bila ditindaklanjuti oleh pemikiran yang matang, terencana, dan sistematis merupakan upaya mengapresiasi terhadap hubungan kita dengan masa lampau yang sesungguhnya mengandung banyak arti dalam menjelaskan berbagai persoalan masa kini.

Berdasarkan uraian di atas, penelitian sejarah ini bertujuan menelusuri sejarah Kerajaan Cirebon dari awal berdirinya, masa kejayaannya sampai masa kemundurannya. Dari penelusuran itu diharapkan dapat meningkatkan pemahaman kita terhadap masa lalu Kerajaan Cirebon.

\section{B. HASIL DAN BAHASAN}

\section{Kerajaan Islam Cirebon}

Kurang lebih satu tahun, setelah Sunan Gunung Jati menetap di Cirebon tepatnya pada tahun 1479 Masehi, Pangeran Cakrabuana selaku penguasa Cirebon menyerahkan tampuk pimpinan kepada Sunan Gunung Jati, keponakannya dan sekaligus sebagai menantunya. Penobatan Sunan Gunung Jati didukung oleh para Wali Allah di Pulau Jawa yang dipimpin oleh Sunan Ampel. Sunan Gunung Jati oleh para wali dianugrahi gelar sebagai penetep/panata agama Islam di tanah Sunda dan sebagai Tumenggung Cirebon. Sejak itu tokoh-tokoh Islam lainnya banyak yang menyerahkan pengikutnya kepada Sunan Gunung Jati. Tokoh-tokoh Islam yang dimaksud tadi antara lain adalah Syekh Datuk Khafi, Syekh Majagung, Syekh Siti Jenar, Syekh Magribi, Pangeran Kejaksan, dan para Ki Gedeng
(Ekadjati, 1991: 103-104, Sulendraningrat, 1984: 34-35).

Dengan demikian, Sunan Gunung Jati merupakan "Pandita Ratu" karena selain sebagai kepala pemerintahan (penguasa) ia juga berperan sebagai Wali Sanga penyebar Islam. Sedangkan oleh kalangan tradisi setempat, ia disebut "Ingkang Sinuhun Kangjeng Susuhunan Jati Purba Panetep Penata Agama Awaliya Allah Kutubid Zaman Kholipatur Rosulullah S.A.W." (Sulendraningrat, 1985: 21, Ekajati, 1991: 37).

Setelah menjadi penguasa langkah awal tindakan politik yang dijalankan oleh Sunan Gunung Jati ialah menggalang kekuatan terlebih dahulu dengan Demak (Ambary, 1995: 13) dan kekuatan-kekuatan Islam lainnya serta melepaskan diri dari kekuasaan Kerajaan Sunda Pajajaran. Sunan Gunung Jati menghentikan kewajiban memberi upeti tahunan berupa garam dan terasi kepada Kerajaan Sunda Pajajaran. Tindakan Sunan Gunung Jati itu membuat Raja Sunda Pajajaran marah dan kemudian mengutus Tumenggung Jagabaya beserta 60 orang pasukannya untuk mendesak supaya penguasa Cirebon menyerahkan upeti. Akan tetapi setibanya di Cirebon, Tumenggung Jagabaya beserta pasukannya tidak menjalankan perintah dari Raja Pajajaran, bahkan "membelot" dan semuanya berkeinginan masuk agama Islam. Mereka tidak kembali lagi ke Pajajaran dan menetap di Cirebon mengabdi kepada Sunan Gunung Jati (Ekadjati, Sulendraningrat, 1984: 35; Atja dan Ayatrohaedi, 1986: 73).

Degan dihentikannya upeti kepada Kerajaan Sunda Pajajaran, itu merupakan pertanda bahwa Cirebon sejak dipegang oleh Sunan Gunung Jati melepaskan diri dari Kerajaan Sunda Pajajaran. Selanjutnya, dimulailah sebuah negara yang bebas dan merdeka serta berdaulat penuh atas rakyat dan wilayahnya.

Upaya Sunan Gunung Jati untuk melepaskan diri dari Kerajaan Sunda Pajajaran tidak mendapat halangan yang berarti. Hal itu dikarenakan adanya beberapa penyebab, yaitu: Pertama, karena Kerajaan Sunda Pajajaran sedang mengalami kemunduran dan kekuatannya makin digerogoti oleh penguasa-penguasa daerah yang ingin 
melepaskan diri dari kekuasaannya, seperti Raja Galuh, Talaga, dan Banten. Kedua, membelotnya Tumenggung Jayabaya beserta pasukannya yang tergolong kuat, mengakibatkan terpukulnya hati Raja Pajajaran, sehingga konsentrasi kepada kerajaan terganggu. Ketiga, Sunan Gunung Jati masih keturunan Prabu Siliwangi, dan keempat, Raja Pajajaran, Sribaduga Maharaja (Prabu Siliwangi) keburu meninggal dunia (1521).

\section{Masa Pasang Kerajaan Cirebon}

Dengan berkuasanya Syarif Hidayatullah atau yang lebih dikenal dengan Sunan Gunung Jati di Cirebon pada tahun 1479 M maka Cirebon menjadi Kesultanan Cirebon. Sunan Gunung Jati naik sebagai penguasa Cirebon setelah ia dilantik sebagai Tumenggung Hidayatullah bin Maulana Sultan Muhammad Syarif Abdullah dan disambut oleh para wali tanah Jawa dengan memberikan gelar Panetep Panatagama Rasul di tanah Sunda atau Ingkang Sinuhun Kanjeng Susuhunan Jati Purba Panetep Panatagama Awlya Allah Kutubid zaman Khalifatur Rasulullah Saw. Ia memerintah dari Keraton Pakungwati. Status kesultanan itu mencerminkan bahwa proses Islamisasi telah berlangsung lama di Cirebon. Hal yang demikian itu dapat dimengerti karena suatu negara tidak mungkin menjadi sebuah kesultanan jika penguasanya (raja dan jajarannya) dan rakyatnya belum memeluk agama Islam.

Pada masa pemerintahan Sunan Gunung Jati (1479 - 1568) Kesultanan Cirebon mengalami perkembangan yang sangat pesat. Pada masa itu, bidang keagamaan, politik, dan perdagangan sangat maju.

Pada masa Sunan Gunung Jati upaya Islamisasi sangat diintensifkan. Penyebaran Islam ke berbagai wilayah terus menerus dilaksanakan. Misalnya, pada tahun 15251526, dilakukan penyebaran Islam ke Banten dengan cara menempatkan putra Sunan Gunung Jati yang bernama Maulana Hasanuddin. Banten berhasil dikuasai setelah Maulana Hasanuddin berhasil menumbangkan pemerintahan Pucuk Umum yang berkedudukan di Banten Girang sebagai penguasa Kadipaten dari Kerajaan Sunda
Pajajaran. Kemudian, Maulana Hasanuddin segera membentuk pemerintahan yang berkedudukan di Surosowan dekat Muara Cibanten (Djajadiningrat, 1983).

Tentu saja penyebaran Islam tidak hanya dilakukan terhadap Banten, ke wilayah lain pun dilakukan. Penyebaran Islam ke wilayah Priangan Timur antara lain ke Galuh pada tahun 1528 dan ke Talaga pada tahun 1530. Memang upaya penyebaran agama Islam tidak semata-mata untuk menyebarkan agama tetapi juga untuk memperluas wilayah. Menurut Nina Herlina Lubis (2003: 187) Kerajaan Cirebon terlibat dalam serangkaian peperangan menghadapi serangan-serangan dari para adipati bawahan Kerajaan Sunda Pajajaran yang ada di sekitar Cirebon, serta tiga kali mengalami pertempuran besar, yaitu pertempuran merebut pelabuhan Sunda Kalapa, pertempuran dengan Rajagaluh, dan pertempuran dengan Talaga.

Dalam pertempuran untuk merebut pelabuhan Sunda Kalapa, Sunan Gunung Jati sebenarnya menerapkan strategi berupa penyelarasan politik dengan ambisi politik yang dilakukan oleh Kesultanan Demak. Hal yang demikian itu dapat dipahami karena antara Cirebon dan Demak mempunyai hubungan kekerabatan yang erat. Upaya penyelarasan itu terlihat dalam usaha penyebaran Islam ke arah barat, yaitu di sepanjang pesisir utara Jawa bagian barat. Dari segi politik, kolaborasi itu terlihat jelas ketika upaya penyebaran Islam itu dilakukan setelah Kesultanan Banten berdiri. Penyerangan ke pelabuhan utama Kerajaan Sunda Pajajaran yang terjadi pada tahun 1527 dilakukan oleh tentara gabungan Demak, Cirebon, dan Banten (Uka Tandrasasmita, 2009: 164).

Penguasaan Islam atas pelabuhan Sunda Kalapa itu jelas sebagai upaya membendung pengaruh Portugis yang sudah menduduki Malaka sejak tahun 1511. Dengan demikian, ketiga kesultanan itu dengan leluasa dapat menyingkirkan Portugis dari jalur lalu lintas perdagangan internasional dan regional dari daerah Maluku ke berbagai pelabuhan di sepanjang pesisir Jawa melalui Selat Sunda (Tanjdrasasmita, 2001: 43 - 64). 
Memang bila ditinjau lebih jauh upaya menguasai pelabuhan Sunda Kalapa mempunyai arti yang sangat penting. Bukankah perdagangan internasional yang dilakukan oleh kesultanan-kesultanan di Nusantara melalui Samudera Hindia ke negeri-negeri Timur Tengah, melalui Teluk Aden sampai ke Afrika Timur, selalu mendapat rintangan di lautan Hindia oleh Portugis sebagai mana yang dikatakan oleh Chauduri (1989), bahwa "kedatangan Portugis di Benua India secara tiba-tiba mengakhiri sistem pelayaran yang damai yang menandai kawasan ini”.

Dengan dikuasainya pelabuhan Sunda Kalapa, pengaruh Portugis dapat dihilangkan. Dengan demikian, pelabuhan-pelabuhan di sepanjang pesisir utara Jawa seperti: Gresik, Sedayu, Tuban, Jepara, Demak, Cirebon, Jakarta, dan Banten menjadi pelabuhan yang ramai. Di pelabuhanpelabuhan itu banyak kelompok-kelompok pedagang dari Arab, Timur Tengah, India, Tionghoa, dan dari negeri-negeri di Asia Tenggara. Tentu saja kondisi seperti itu membuat Cirebon mengalami kemajuan yang pesat di bidang perdagangan.

Penyebaran agama Islam yang disertai motif memperluas wilayah tidak semuanya dilakukan melalui peperangan juga tidak hanya di arahkan ke wilayah pantai. Upaya Islamisasi juga dilakukan dengan cara damai ke wilayah pedalaman seperti ke daerah Babadan, Kuningan, Indramayu, dan Karawang. Namun demikian, upaya itu tetap saja tidak dapat dilepaskan dari motif ekonomi. Menurut Singgih Tri Sulistyo (1997: 82) upaya Islamisasi dilandasi motif untuk memperbesar posisi Cirebon di bidang perdagangan dan pelayaran dengan cara menguasai daerah pedalaman yang menjadi sumber penghasil komoditas perdagangan seperti beras dan kayu, juga sekaligus tempat mensuplai barang-barang dari luar.

Adapun sistem politik yang dikembangkan oleh Sunan Gunung Jati didasarkan pada asas desentralisasi yang berpola kerajaan pesisir. Pelabuhan menjadi bagian yang sangat penting dengan pedalaman sebagai unsur penunjang yang vital. Strategi politik desentralisasi itu dilakukan dengan menerapkan program pemerintahan yang bertumpu pada intensitas pengembangan dakwah Islam ke seluruh wilayah bawahannya di tanah Sunda dengan didukung oleh perekonomian yang menitikberatkan pada perdagangan dengan berbagai negara seperti Campa, Malaka, India, Cina, dan Arab. Untuk menunjang misi pemerintahannya itu, Sunan Gunung Jati mengisi personil jajaran pemerintahannya dengan para kerabatnya dan para ulama (Sunardjo, 1983: 77-78).

Pada masa pemerintahan Sunan Gunung Jati, selain perluasan wilayah juga dilakukan pembangunan sarana dan prasarana umum (Herlina, et.al., 2003: 180-181). Upaya pembangunan itu di antaranya: (1) Pada tahun 1483, keraton lama Dalem Pakungwati yang dulu dibangun oleh Cakrabuwana diperluas dan ditambah dengan bangunan-bangunan pelengkap juga tembok keliling setinggi 2,5 meter dengan ketebalan $80 \mathrm{~cm}$ pada areal tanah seluas 20 hektar. Selanjutnya, untuk keamanan dibangun tembok setinggi 2 meter mengelilingi ibukota, meliputi areal seluas 50 hektar. Tembok keliling itu tentu saja dilengkapi dengan pintu gerbang, yang salah satu dari pintu gerbang itu diberi nama Lawang Gada; (2) Pembangunan pangkalan perahu yang terletak di sebelah tenggara keraton di tepi Sungai Kriyan. Pangkalan perahu itu dilengkapi dengan gapura yang disebut Lawang Sanga, bengkel perahu, istal kuda kerajaan, dan pos-pos penjagaan; (3) Di pelabuhan Muara Jati dilakukan perbaikan dan penyempurnaan bangunan-bangunan untuk fasilitas pelayaran seperti mercu suar yang dulu dibuat oleh Ki Ageng Tapa dengan dibantu oleh orang-orang Cina. Di pelabuhan ini dibangun pula bengkel untuk memperbaiki perahu berukuran besar yang mengalami kerusakan dengan memanfaatkan orang-orang Cina ahli pembuat Jung yang dahulu dibawa oleh Laksamana Cheng Ho. Pelabuhan Muara Jati pada masa itu merupakan pasar tempat transaksi perdagangan rempah-rempah, beras, hewan potong, dan tekstil. Oleh sebab itu, di sekitar Muara Jati banyak pedagang asing bermukim seperti dari Cina dan Arab; (4) Pembangunan sarana transportasi dilaksanakan sebagai upaya mempercepat pertumbuhan ekonomi. Untuk itu dibangunlah sarana transportasi penunjang pelabuhan laut 
berupa saluran transportasi melalui sungai dan jalan darat. Mengenai jalan darat, pembangunan jalan besar dimulai dari alunalun keraton Pakungwati ke pelabuhan Muara Jati. Pembangunan jalan itu tujuannya agar para pedagang asing atau para utusan dari kerajaan lain yang masuk ke pelabuhan Muara Jati dapat secara mudah bertemu dengan Sunan Gunung Jati apabila mereka mau menghadap atau membicarakan sesuatu; (5) Untuk menjaga dan memelihara keamanan dibentuk pasukan keamanan yang disebut Pasukan Jagabaya dengan jumlah dan kualitas yang memadai. Pasukan Jagabaya ini di tempatkan di pusat kerajaan dan tentu saja di setiap wilayah yang sudah dikuasai oleh Kesultanan Cirebon.

Sunan Gunung Jati yang menjadi raja di Kesultanan Cirebon adalah seorang anggota Wali Songo. Dengan demikian, segala aktivitasnya tentu saja tidak terlepas dari upaya menyebarkan agama Islam. Untuk itulah, pada tahun 1480, Sunan Gunung Jati mendirikan Masjid Agung Sang Cipta Rasa yang terletak di samping kiri keraton dan di sebelah barat alun-alun. Dalam membangun Masjid Agung Sang Cipta Rasa itu, Sunan Gunung Jati dibantu oleh Sunan Bonang dan Sunan Kalijaga. Adapun yang menjadi arsitek dari masjid itu ialah Raden Sepat, mantan arsitek Majapahit. Sunan Gunung Jati menjadikan masjid sebagai pusat dakwah Islam, oleh karena itu di setiap wilayah bawahan Cirebon dibangun masjid jami (Herlina, dkk., 2003: 190).

Sebagai pemimpin politik dan agama, Sunan Gunung Jati membentuk sistem dan struktur kenegaraan yang didasarkan pada paham kekuasaan religius. Adapun esensi dari paham kekuasaan religius adalah meletakan kekuasaan politik pada karakter adiduniawi dan adimanusiawi (Suseno, 1994: 31-32). Menurut Moertono (1981: 2627) sang pemimpin bukan lagi manusia biasa tetapi manusia yang memiliki kemampuan supranatural. Raja menjadi medium yang menghubungkan manusia (mikrokosmos) dengan alam gaib (makro-kosmos). Dengan demikian, misi pemerintahan Sunan Gunung Jati bentuknya merupakan perpaduan antara sistem pengelolaan negara dengan dakwah agama Islam sehingga aspek-aspek pemerintahan, pengendalian masyarakat, dan pengembangan agama menyatu menjadi bagian yang tidak terpisahkan (Herlina, et.al., 2003: 186).

Begitulah sistem pemerintahan di Kesultanan Cirebon. Artinya, dalam urusan kenegaraan, pengembangan agama mendapat prioritas yang utama. Penyebaran agama Islam dilakukan di dalam dan di luar wilayah Cirebon, baik ke daerah pesisir maupun ke daerah pedalaman. Penyebaran agama Islam ke daerah pedalaman Tatar Sunda dilakukan melalui jalur: (a) CirebonKuningan-Talaga-Ciamis, (b) CirebonKadipaten-Majalengka-Damaraja-Garut, (c) Cirebon-Sumedang-Bandung, (d) CirebonTalaga-Sagalaherang-Cianjur, (e) BantenJakarta-Bogor-Sukabumi, dan (f) BantenBanten Selatan-Bogor-Sukabumi.

Sebagai manusia yang paripurna, Sunan Gunung Jati diyakini memiliki ilmu yang mumpuni baik di bidang agama maupun di bidang kenegaraan, ekonomi, kemasyarakatan, kesehatan, keluarga, pendidikan dan sebagainya. Di bidang agama, ilmunya meliputi ilmu fiqh, syari'ah, tasawuf dan mistik. Di bidang kesehatan, Sunan Gunung Jati berdakwah mengenai pengobatan herbal, yaitu penggunaan daundaunan dan akar-akaran untuk mengobati penyakit. Selain itu, pengobatan batin yang semula diatasi dengan pengobatan spiritual, firasat, jampi-jampi, dan mantra-mantra oleh Sunan Gunung Jati diganti dengan memakai doa-doa Islam (Suryanegara, 1995: 75-94).

Pada bidang kebudayaan, terlihat dari gambaran simbol-simbol kosmis dan simbol yang berasal dari ajaran agama Islam. Simbol kosmis diwujudkan dalam bentuk payung sutera berwarna kuning dengan kepala naga. Payung itu melambangkan semangat perlindungan dari raja kepada rakyatnya. Adapun simbol-simbol yang berasal dari ajaran Islam dibagi ke dalam empat tingkatan, yaitu: (a) syariat, yang disimbolkan dengan wayang, adapun wayang itu sendiri adalah perwujudan dari manusia dengan dalangnya Allah, (b) tarekat yang disimbolkan dengan barong, (c) hakekat yang disimbolkan dengan topeng, dan (d) ma'rifat yang disimbolkan dengan ronggeng. 
Keempat simbol itu, yakni wayang, barong, topeng, dan ronggeng merupakan empat jenis pertunjukan kese-nian masyarakat Cirebon dan masyarakat Jawa pada umumnya (Siddique, 1977: 79-82).

Simbol-simbol di atas senantiasa muncul dalam berbagai bentuk acara selamatan yang menjadi tradisi di bulanbulan tertentu dan perayaan-perayaan hari besar Islam yang berasal dari tradisi Walisongo, termasuk Sunan Gunung Jati, seperti upacara sekaten sebagai perayaan memperingati maulid Nabi Muhammad SAW, yang dilangsungkan di seluruh kerajaan Islam Jawa. Perayaan sekaten ini biasanya dipusatkan di alun-alun ibu kota kerajaan yang dapat dinikmati bersama khalayak ramai pada umumnya. Perayaan sekaten itu sendiri dimulai tujuh hari sebelum tiba peringatan hari Maulid Nabi Muhammad SAW yang tepatnya jatuh pada tanggal 12 Rabi'ul Awal. Sekaten diakhiri dengan upacara Garebeg, yaitu upacara yang berpuncak pada siratun nabiy (pembacaan riwayat Nabi Muhammad SAW) dan sedekah sultan, yaitu membagi-bagikan makanan hadiah dari sultan di Masjid Agung. Acara ini dihadiri oleh sultan dan pembesar-pembesar kerajaan. Sekaten ini satu-satunya upacara dan perayaan terbesar karena pergelarannya merupakan upacara memperingati hari lahir Nabi Muhammad SAW. Pada saat Garebeg itulah, adipatiadipati, raja-raja muda, bupati-bupati, pembesar-pembesar wilayah kerajaan diterima menghadap sultan untuk menunjukkan sikap hormat dan baktinya kepada sultan sembari mangayu bagja pada hari yang mulia dan meriah itu (Saksono, 1995: 150-151).

Upacara peringatan maulid Nabi Muhammad SAW di Keraton Cirebon mulai diadakan dan dilaksanakan secara besarbesaran ketika diadakan pengangkatan Sunan Gunung Jati sebagai wali kutub pada tahun 1470 M. Perayaan itu di kalangan masyarakat Cirebon dikenal dengan iringiringan panjang jimat (Herlina, et.al., 2003: 184-185). Aktifitas perayaan keagamaan Islami yang dilakukan oleh kerabat keraton menunjukkan bahwa Sunan gunung Jati dan keturunannya dalam struktur sosial dimasukkan ke dalam anak bangsa kaum santri sebagai legitimasi peran, fungsi, dan kedudukan Sunan Gunung Jati sebagai Panatagama (Siddque, 1977: 91).

Sunardjo (1996: 38-40) merinci keberhasilan masa pemerintahan Sunan Gunung Jati sebagai berikut: (1) Wilayah bawahan Kerajaan Cirebon sampai tahun 1530 M sudah meliputi separuh dari Provinsi Jawa Barat (sekarang) dan Provinsi Banten dengan jumlah penduduk pada saat itu sekitar 600.000 orang yang sebagian besar masih beragama nonIslam; (2) Pelabuhan-pelabuhan penting di sepanjang pantai utara Jawa Barat seluruhnya sudah dapat dikuasai oleh Kerajaan Cirebon; (3) Telah dilakukan pembangunan masjid jami di ibu kota dan di berbagai wilayah bawahan Kerajaan Cirebon, serta langgar-langgar di berbagai pelabuhan; (4) Perluasan dan pembangunan Keraton Pakungwati sehingga sesuai dengan fungsi dan posisinya sebagai bangunan utama pusat pemerintahan kerajaan yang berdasarkan Islam; (5) Tembok keliling keraton berikut beberapa pintu gerbang, pangkalan perahu kerajaan, pospos penjagaan keamanan, instal kuda kerajaan, bangunan untuk kereta kebesaran kerajaan, pedati-pedati untuk pengangkutan barang, dan sitinggil/pancaniti (bangunan untuk pengadilan), serta alun-alun telah selesai dibangun dan diperindah; (6) Telah selesai dibangun tembok keliling ibu kota meliputi areal seluas 50 hektar dilengkapi dengan beberapa pintu gerbang dan pos jagabaya; (7) Telah selesai dibangun jalan besar utama menuju Pelabuhan Muarajati dan jalan-jalan di ibu kota serta jalan-jalan yang menghubungkan ibu kota dengan wilayah-wilayah bawahannya; (8) Pasukan Jagabaya jumlahnya sudah cukup banyak, organisasinya sudah ditata dengan komandan tertingginya dipegang oleh seorang tumenggung yang disebut Tumenggung Jagabaya; (9) Dalam urusan penyelenggaraan pemerintahan, baik di pusat kerajaan maupun di wilayah bawahan telah diatur dalam tata aturan pemerintahan yang cukup rapi. Sunan Gunung Jati telah memberlakukan gelar-gelar jabatan.

\section{Masa Surut Kerajaan Cirebon}

Panggilan hati Sunan Gunung Jati rupanya lebih cenderung pada upaya penyebaran agama Islam dari pada menjadi 
raja. Oleh karena itu pada tahun 1528 urusan pemerintahan kesultanan ia serahkan kepada Pangeran Pasarean, putra Sunan Gunung Jati dari Nyai Tepasari. Selanjutnya, Sunan Gunung Jati lebih mengkhususkan diri menyebarkan agama Islam ke daerah pedalaman (Ekadjati, 1991: 107-108). Tentu saja Pangeran Pasarean statusnya hanya mewakili saja, artinya belum menjadi raja, sebab Sunan Gunung Jati masih hidup dan belum menyerahkan statusnya. Dengan posisinya itu, jelaslah bahwa Pangeran Pasarean telah dipromosikan oleh Sunan Gunung Jati sebagai calon penggantinya dikemudian hari. Akan tetapi, meskipun ia telah mewakili Sunan Gunung Jati selama 18 tahun, ia tidak sempat mewarisi tahta kerajaan karena ia keburu meninggal dunia di Demak pada tahun 1546. Urusan pemerintahan kemudian diwakili oleh Fadhillah Khan, menantu Sunan Gunung Jati (Ekadjati, 1991: 64).

Setelah Pangeran Pasarean meninggal dunia, selanjutnya yang dipromosikan untuk menggantikan Sunan Gunung Jati ialah Pangeran Sawarga, putra Pangeran Pasarean, cucu Sunan Gunung Jati. Ia telah menduduki jabatan penting dalam birokrasi Kesultanan Cirebon sehingga namanya berubah menjadi Pangeran Dipati Carbon. Akan tetapi ia meninggal dunia terlebih dahulu, yaitu pada tahun 1565 (Ekadjati, 1991: 88).

Pada tahun 1568 Sunan Gunung Jati meninggal dunia, roda pemerintahan Kesultanan Cirebon tetap dijalankan oleh Fadhillah Khan sampai ia meninggal pada tahun 1570. Setelah itu, yang naik tahta adalah cicit Sunan Gunung Jati yang bernama Pangeran Emas putra Pangeran Swarga Dipati Carbon dari perkawinan dengan Nhay Mas Ratu Wanawati Raras, putri Fadhillah Khan.

Pangeran Emas kemudian bergelar Panembahan Ratu I, ia memerintah Kesultanan Cirebon selama 79 tahun, yaitu dari tahun 1570 sampai 1649 M. Pada masa Panembahan Ratu I di Cirebon tidak terjadi masalah apapun. Hal yang demikian itu terjadi karena kondisi Cirebon pada masa itu sangat kondusif. Kerajaan Sunda sudah tidak menjadi ancaman lagi bagi eksistensi
Kesultanan Cirebon. Demikian pula dengan Kerajaan Banten. Pada masa itu Banten masih tetap konsisten memandang Cirebon sebagai sumber pertama eksistensi kesultanannya. Selain itu, terjalin hubungan yang erat dengan Kerajaan Pajang dan juga hubungan dagang dengan luar negeri berjalan lancar. Pelabuhan-pelabuhan sebagai aset Kesultanan Cirebon yang amat penting terjaga keamanannya sehingga kapal-kapal dagang asing makin banyak yang singgah untuk melakukan transaksi dengan masyarakat Cirebon (Sunardjo, 1996: 44).

Namun demikian, pada masa Panembahan Ratu I Kesultanan Cirebon tidak lagi melebarkan wilayahnya ke daerah-daerah lain, karena pada waktu itu posisi Cirebon terjepit di antara dua kerajaan besar, yaitu Banten di barat dan Mataram di timur. Sebenarnya Cirebon bisa saja diruntuhkan baik oleh Banten maupun oleh Mataram mengingat kekuatan angkatan bersenjata Banten atau Mataram lebih kuat dari Cirebon. Akan tetapi kedua kerajaan tersebut masih menghormati Cirebon. Banten menghormati Cirebon sebagai tahta leluhurnya, yaitu Sunun Gunung Jati, sedangkan Mataram memandang Cirebon sebagai guru dan keramat (Ekadjati, 1991).

Bukan mustahil Cirebon, yang selalu bersahabat dengan Mataram, dalam banyak hal menjadi teladan bagi Mataram. Mungkin Sitiinggil yang terdapat di Keraton Cirebon pada tahun 1625 ditiru oleh Susuhunan untuk keratonnya dan mungkin pula makam keramat Sunan Gunung Jati dipakai sebagai contoh untuk makamnya di Wonogiri. Ketika Sidang Raya Kerajaan Mataram berlangsung pada tahun 1636, rupanya Panembahan Ratu yang dituakan dan dihormati diundang untuk datang ke Mataram dengan maksud untuk memperbesar kewibawaan Susuhunan (De Graaf, 1986: 292).

Pada masa Panembahan Ratu I ternyata Cirebon lebih dekat ke Mataram daripada ke Banten. Sebagai contoh Putri Ratu Ayu Sakluh yang merupakan kakak perempuan Panembahan Ratu I menikah dengan Sultan Agung Mataram. Dari pernikahan itu, Sultan Agung berputra Susuhunan Amangkurat I. Kelak salah 
seorang putri Susuhunan Amangkurat I bersuamikan Panembahan Girilaya dari Cirebon (Atja dan Ajatrohaedi, 1986: 22; Atja, 1986: 72 dalam Edi S. Ekadjati, 1991: 112; Tjandrasasmita, 1995: 144). Selain itu, menurut F. Dee Haan (1912: 38), juga ditandai dengan dibangunnya kuta (dinding) yang mengitari keraton Pakungwati. Kuta yang mengelilingi keraton Cirebon itu dibangun kurang lebih pada 1590 yang pembangunannya merupakan persembahan Senapati Mataram terhadap Panembahan Ratu I Cirebon.

Sepeninggalnya Panembahan Ratu I pada 1649 , kedudukannya sebagai kepala pemerintahan Cirebon digantikan oleh cucunya yang bernama Pangeran Putra atau disebut juga Raden Rasmi dan bergelar Panembahan Adiningkusuma atau bergelar Panembahan Ratu II, setelah meninggal dunia, ia lebih dikenal dengan Panembahan Girilaya, karena dimakamkan di sebuah bukit yang bernama Girilaya, yang letaknya di sebelah timur Wonogiri, Jogjakarta (Tedjasubrata, $1966: 112$ ).

Pada masa pemerintahan Panembahan Ratu II, Cirebon mulai mengalami masalah dalam bidang politik. Raja Mataram yaitu Amangkurat I yang juga mertuanya meminta agar Panembahan Ratu II membujuk Banten untuk bersahabat dengan Mataram dan mau menghentikan serangannya terhadap Belanda. Panembahan Ratu II mau tidak mau menuruti kemauan Amangkurat I. Ia beberapa kali berkunjung ke Banten untuk membujuk sultan Ageng Tirtayasa agar mau bergabung dengan Mataram dan menghentikan serangan ke Belanda, tetapi usahanya itu gagal. Bahkan Sultan Ageng Tirtayasa mengajaknya untuk bergabung dengan Banten daripada dengan Mataram. Sultan Ageng Tirtayasa juga memperingatkan bahwa Mataram dapat mengancam kedaulatan Cirebon (Sunardjo, 1996: 53-54).

Kegagalan Panembahan Ratu II di dalam membujuk Banten membawa akibat yang fatal. Amangkurat I merasa kecewa dan menganggap Panembahan Ratu II telah bersekutu dengan Banten. Karena itulah pada tahun 1662 Amangkurat I mengundang Panembahan Ratu II ke Mataram untuk menghadiri upacara penghormatan. Tentu saja Panembahan Ratu II tidak bisa menolak undangan tersebut. Ia bersama kedua putranya, yaitu Pangeran Martawijaya dan Pangeran Kartawijaya datang ke Mataram. Sesampainya di Mataram dan setelah upacara penghormatan itu selesai, Panembahan Ratu II beserta kedua anaknya tidak diperbolehkan pulang ke Cirebon. Rupanya undangan itu tidak semata dimaksudkan sebagai penghormatan tetapi juga sebagai pertanggungjawaban Panembahan Ratu II yang gagal melaksanakan misi Mataram. Di Mataram Panembahan Ratu II dengan kedua putranya menjadi tahanan politik meskipun demikian Panembahan Ratu II tetap diakui sebagai Raja Cirebon. Mereka tinggal di kompleks perumahan bangsawan Mataram dan diperlakukan secara baik (Herlina, et. al., 2003: 196).

Menurut Burger (1962: 59) tindakan itu merupakan kebijakan politik pemerintahan Susuhunan Amangkurat I terhadap penguasa-penguasa pesisir. Mataram di bawah Susuhunan Amangkurat I berusaha mencurahkan seluruh tenaga untuk dapat mengendalikan penguasa-penguasa di daerah pesisir guna kepentingannya. Cara yang dipergunakan oleh Mataram itu adalah dengan jalan menjadikan penguasa-penguasa pesisir sebagai abdi istana. Hal itu, dimaksudkan agar penguasa daerah pesisir yang cenderung bersikap terbuka terhadap pengaruh luar menjadi kurang membahayakan dan sekaligus kekuasaan mereka bisa diawasi lebih ketat.

Selama Panembahan Ratu II dan kedua puteranya berada di Mataram, pemerintahan sehari-hari di Cirebon dipegang oleh putra ketiganya, yaitu Pangeran Wangsakerta yang tidak ikut serta ke Mataram. Dalam menjalankan roda pemerintahannya, Pangeran Wangsakerta selalu diawasi secara ketat oleh orang-orang Mataram yang ditugaskan oleh Susuhunan Amangkurat I. Hal yang demikian itu jelas menunjukkan bahwa Cirebon sudah kehilangan kedaulatannya. Apa yang pernah dikatakan oleh Sultan Ageng Tirtayasa kepada Panembahan Ratu II bahwa Mataram dapat mengancam kedaulatan Cirebon menjadi kenyataan.

Selama bertahun-tahun mereka tinggal di Mataram, sampai akhirnya pada tahun 1667 Panembahan Ratu II meninggal 
dunia dan dimakamkan di Girilaya. Sejak saat itu Panembahan Ratu II sering disebut dengan nama Panembahan Girilaya. Sepuluh tahun kemudian yaitu sekitar tahun 1677, Raden Trunojoyo mengadakan serangan besar- besaran terhadap keraton Mataram. Serangan itu bukan saja berhasil menduduki ibukota Mataram, melainkan juga dapat membebaskan kedua Pangeran Cirebon, yaitu Pangeran Martawidjaja dan Pangeran Kertawidjaja dari cengkraman Sunan Amangkurat I. Selanjutnya kedua Pangeran Cirebon itu dibawa oleh pasukan Raden Trunojoyo ke Kediri. Dari Kediri kedua Pangeran tersebut diambil oleh utusan Sultan Ageng Tirtayasa ke Banten (Ekadjati, 1991: 115-116; Sunardjo, 1983: 139; Atja, 1988: 10).

Di Banten Sultan Ageng Tirtayasa mengangkat kedua pangeran itu sebagai sultan Cirebon dan menetapkan wilayah dan rakyatnya masing-masing. Pangeran Martawijaya menjadi Sultan Sepuh dan Pangeran Kartawijaya menjadi Sultan Anom. Sedangkan Pangeran Wangsakerta diangkat menjadi Panembahan Cirebon tetapi tanpa memiliki wilayah kekuasaan dan keraton secara formal (Ekadjati, 1991: 93).

Menurut catatan Brandes (1911: 24), mereka kembali ke Cirebon, tahun 1678. Dengan pengakuan Sultan Ageng Tirtayasa, maka Pangeran Martawidjaja (Pangeran Samsudin) menjadi Sultan Sepuh/Kasepuhan yang pertama, Pangeran Kertawidjaja (Pangeran Badrudi/Komarudin) menjadi Sultan Anom/Kanoman yang pertama, sedangkan Pangeran Wangsakerta (Raden Godang) menjadi Panembahan Cirebon yang pertama/Sultan Cirebon (Atja, 1988: 10-11). Keputusan Sultan Ageng Tirtayasa menyebabkan Cirebon terbagi menjadi tiga bagian dan mulai saat itu Cirebon berada di bawah pengaruh dominasi Banten.

Sultan Sepuh (Pangeran Samsudin) kemudian menempati Keraton Pakungwati sebagai keratonnya (sekarang letaknya di sebelah timur Keraton Kasepuhan). Sultan Anom (Pangeran Badrudin) menempati bekas rumah pertama Pangeran Cakrabuana untuk dijadikan keratonnya. Tempat itu sekarang termasuk ke dalam wilayah kelurahan Lemah Wungkuk Kotamadya
Cirebon. Adapun Sultan Cerbon (Panembahan Cirebon) untuk sementara waktu tinggal bersama-sama dengan Sultan Sepuh di kompleks Keraton Pakungwati (Sunardjo, 1983: 153).

Sejak saat itu pula pemakaian gelar di Cirebon berubah, yaitu dari panembahan menjadi sultan. Pangeran Martawijaya memakai gelar Sultan Sepuh Abil Makarimi Muhammad Samsudin (1677-1703) dan Pangeran Kartawijaya memakai gelar Sultan Anom Abil Makarimi Muhammad Badrudin (1677-1723). Gelar Sultan itu diberikan oleh Sultan Ageng Tirtayasa ketika ia melantik kedua Pangeran Cirebon itu di ibu kota Banten. Sebagai Sultan, kedua pangeran dari Cirebon itu mempunyai kekuasaan penuh atas wilayah dan rakyatnya dan juga memiliki keraton masing-masing. Namun demikian, Sultan Ageng Tirtaysa tidak mengangkat anak laki-laki ketiga dari Panembahan Ratu II, yang bernama Pangeran Wangsakerta sebagai sultan. Ia hanya diangkat sebagai Panembahan Cirebon dengan gelar Pangeran Abdul Kamil Muhammad Nasarudin atau Panembahan Tohpati (1677-1713). Dengan demikian, ia tidak memiliki wilayah kekuasaan dan keraton sendiri. Tempat tinggalnya hanya berupa rumah besar biasa yang terletak di sebelah Timur Keraton Pakungwati (Subagja, 1990: 54-55).

Dengan terbaginya Cirebon menjadi dua kesultanan yang sederajat dan satu panembahan, sulit bagi Cirebon untuk mengembalikan lagi kebesaran dan kewibawaan yang pernah diraih semasa Cirebon dipegang oleh Sunan Gunung Jati. Ketiga orang itu mempunyai konsep yang berbeda. Sehingga muncullah persaingan bahkan konflik di antara ketiganya. Untuk meredakan persaingan yang keras itu, semua pihak meminta bantuan Kompeni Belanda untuk menyelesaikannya (Herlina, et.al., 2003: 197).

Kondisi semacam itu tentu saja dimanfaatkan oleh Kompeni Belanda untuk menanamkan kekuasaannya di Cirebon. Kompeni Belanda menyambut baik permintaan dari pihak Cirebon untuk bertindak sebagai penengah yang dapat menyelesaikan konflik di kalangan elit Cirebon, sambil 
mencari peluang untuk mengambilalih kekuasaan di Cirebon.

Sejak saat itu maka dimulailah suatu era perjanjian, berbagai perjanjian diadakan oleh pihak Kompeni Belanda dengan kedok mendamaikan para elit Cirebon tetapi dibalik itu semua diprogramkan upaya merebut kekuasan secara bertahap namun pasti. Pada tanggal 4 Desember 1685, 8 September 1688, dan 4 Agustus 1699 dilakukan perjanjian kesepakatan di antara penguasa Cirebon disaksikan oleh para pejabat Kompeni Belanda. Dalam teks perjanjian itu dinyatakan bahwa Gubernur Jenderal Kompeni dan Raad van Nederlandsch Indie bertindak sebagai pemrakarsa dan pelindung Kesultanan Cirebon dengan perantaraan masing-masing Kapten Francois Tack, Johanes de Hartog, dan Komisaris Kompeni Cirebon. Adapun perjanjian tahun 1688 dan 1699 ditujukan secara tersurat untuk memperbaiki hubungan persaudaraan di antara tiga keluarga Keraton Cirebon. Dalam naskah perjanjian dinyatakan secara tersurat tentang derajat kedudukan di antara ketiganya. Sultan Sepuh berada pada posisi paling atas, kemudian Sultan Anom pada posisi kedua, dan Panembahan Cirebon pada posisi ketiga. Urutan kedudukan itu tentu saja berlaku terhadap putra mahkota masing-masing (Ekadjati, 1991: 81-82).

Selain mengatur masalah derajat kedudukan para sultan, perjanjian itu juga mengatur tentang banyak hal, yaitu: (1) yang berhubungan dengan jalannya pemerintahan, seperti; pengeluaran pemerintah, pembagian hasil dari pelabuhan, penerimaan dan jawaban surat, penerimaan dan penyampaian pesan kepada utusan dari negara lain, dan pelaksanaan upacara rutin di alun-alun; (2) yang berhubungan dengan rakyat, seperti; pembuatan kampung, pembuatan jalan, pembuatan dan perbaikan pengairan, pengadilan, pembuatan stempel, perselisihan para pedagang, pembagian pendapatan dan hasil tanah, pengolahan Bandar pelabuhan, pengangkatan dan pemberhentian pejabat kerajaan, dan penetapan putra mahkota, yaitu Pangeran Dipati anom dan Pangeran Ratu (Ekadjati, 1991: 81-82). Dari berbagai penjanjian itu secara tidak langsung para penguasa Cirebon menerima dan mengakui pengaruh kekuasaan Kompeni Belanda.

Begitulah perkembangan politik di Cirebon. Keadaan Cirebon makin parah dan penguasa-penguasa Cirebon sudah tidak bisa berbuat banyak. Secara politis, Cirebon berada di bawah perlindungan kekuasaan Kompeni Belanda. Kondisi itu semakin rumit setelah Sultan Sepuh I meninggal dunia (1697). Harta benda kasepuhan dibagi dua kepada Pangeran Dipati dan Pangeran Aria Adiwidjaja, namun mengenai siapa penguasa yang paling utama di Cirebon, kembali menimbulkan pertentangan yang sengit sehingga mengundang kembali pihak kompeni untuk menjadi penengah lagi.

Pengaruh Kompeni sangat terlihat dalam kontrak tertanggal 4 Agustus 1699 yang antara lain menetapkan bahwa Sultan Anom 1 menempati derajat pertama, Panembahan Cirebon menempati derajat kedua, dan kedua putera Sultan Sepuh 1, yaitu Pangeran Dipati Anom dan Pangeran Aria Adiwidjaja menempati derajat ketiga dalam urusan kepemerintahan di kesultanan Cirebon (Ekadjati, 1991: 123). Dengan demikian, di Cirebon ada empat raja. Kemudian pada tahun 1773 jumlahnya berkurang menjadi tiga orang raja setelah Panembahan Cirebon meninggal dunia. Karena Panembahan Cirebon tidak berputera maka peninggalannya dibagi dua, yaitu kepada Sultan Sepuh dan Sultan Anom (Veth, 1878: 453; Hageman, 1852: 246).

Melalui berbagai perjanjian lambat laun Cirebon jatuh ke tangan Kompeni Belanda dan pada tahun 1681 Kompeni Belanda berhasil menanamkan dominasinya secara penuh. Hal yang demikian itu dapat dilihat dari perjanjian antara Cirebon dengan Kompeni Belanda tanggal 7 Januari 1681. Adapun isi penjanjian itu adalah: (1) Kompeni memperoleh hak monopoli impor pakaian, kapas, dan opium. Semuanya itu bebas dari bea impor, padahal sebelumnya keraton mengenakan bea impor sebesar $2 \%$ dari nilai barang; (2) Kompeni memperoleh hak monopoli ekspor komoditas seperti lada, kayu, gula, beras, dan produk-produk lain yang dikehendaki oleh Kompeni; (3) Tanaman lada yang diusahakan di Cirebon diatur oleh Kompeni dan Kompeni juga yang menentukan harganya; (4) Pelayaran 
pribumi harus mendapatkan lisensi dari VOC dan sangat dibatasi. Tidak semua kapal boleh masuk, kecuali atas ijin dari VOC (Herlina, et.al., 2003: 201).

Dari isi perjanjian tersebut jelaslah bahwa secara politis maupun militer, Cirebon telah berada di bawah dominasi Kompeni Belanda. Kota Cirebon berada di bawah kontrol Kompeni Belanda. Adapun para penguasa Kesultanan Cirebon pada kondisi semacam itu hanyalah berperan sebagai perantara antara kompeni dengan masyarakat pedesaan di pedalaman. Namun demikian, rupanya pihak kompeni masih belum puas juga dengan keadaan itu, karena pihak keraton ternyata masih mempunyai kekuatan ekonomis agraris. Untuk itulah pihak kompeni pun akhirnya berhubungan langsung dengan masyarakat sehingga pihak Keraton Cirebon kehilangan sumber daya ekonominya.

Dengan demikian, sumber ekonomi Kesultanan Cirebon baik di pelabuhan maupun di pedalaman dikuasai sepenuhnya oleh pihak kompeni. Benteng VOC menjadi pusat perdagangan sedangkan keraton berhenti dari aktifitas perdagangan. Keraton akhirnya hanya bisa melakukan aktifitas di bidang kesenian, kerohanian, gaya hidup, dan upacara-upacara keraton yang adiluhung. Cirebon terpuruk dan akhirnya, pada tahun 1809, Gubernur Jenderal Daendels menghapus kekuasaan para Sultan Cirebon (Herlina, et.al., 2003: 201-203).

\section{PENUTUP}

Kesultanan Cirebon didirikan oleh Syarif Hidayatullah pada tahun 1479 M. Syarif Hidayatullah yang naik ke panggung kekuasaan dengan gelar Tumenggung Syarif Hidayatullah bin Maulana Muhammad Syarif Abdullah disambut oleh para wali tanah Jawa dengan memberi gelar Panetep Panatagama Rasul di Tanah Sunda atau Inkang Sinuhun Kanjeng Susuhunan Jati Purba Panetep Panatagama Awlya Allah Kutubid zaman Khalifatur Rasulullah, sudah memberikan indikasi dari awal bahwa dia seorang pemimpin yang istimewa.

Istimewa karena ia seorang wali yang sekaligus juga seorang raja. Sebagai seorang wali, ia mempunyai ilmu agama yang mumpuni dan berahlak mulia sehingga sangat terhormat di mata umatnya. Sebagai seorang raja, ia mempunyai keturunan bangsawan baik dari garis ayah maupun dari garis ibu, sehingga ia memiliki legitimasi yang kuat.

Selama kepemimpinannya (14791568 M), Kerajaan Cirebon mengalami masa keemasannya. Alasan mengapa pada masa kepemimpinannya disebut zaman keemasan bagi Kerajaan Cirebon karena alasan berikut ini: (1) Pada masa itulah yang pada awalnya status Cirebon sebagai bawahan Kerajaan Sunda berubah menjadi negara yang merdeka; (2) Syarif Hidayatullah (yang setelah meninggal disebut sebagai Sunan Gunung Jati) berhasil melebarkan wilayah kekuasaannya meliputi separuh Jawa Barat dan Banten (sekarang) dengan rakyat kurang lebih berjumlah 600.000 jiwa; (3) Berhasil mengislamkan penduduk yang berada di wilayah kerajaannya; (4) Melaksanakan pembangunan baik infra struktur maupun supra struktur dalam berbagai bidang kehidupan. Antara lain, berhasil menguasai pelabuhanpelabuhan penting di pantai Utara Jawa Barat sekaligus membangunnya, membangun keraton, membuat jalan untuk memperlancar mobilitas dan mempercepat pertumbuhan perekonomian, membentuk pasukan keamanan yang kuat, menyelenggarakan sistem pemerintahan yang baik, mendirikan masjid di seluruh wilayah kekuasaannya, dan mengadakan hubungan luar negeri yang bersahabat.

Lewat berbagai langkah yang dilakukan oleh Sunan Gunung Jati, Kesultanan Cirebon mengalami kemajuan yang pesat di berbagai bidang sehingga Kesultanan Cirebon tumbuh menjadi negara yang kuat. Kesultanan Cirebon menjadi negara yang disegani oleh negara-negara lainnya. Adapun setelah Sunan Gunung Jati meninggal dunia secara perlahan Kesultanan Cirebon mengalami kemunduran bahkan keruntuhan. Namun demikian, nama Sunan Gunung Jati masih dihormati dan diidolakan sampai zaman sekarang. 


\section{DAFTAR SUMBER}

Adeng, et. al., 1998.

Kota Dagang Cirebon sebagai

Bandar Jalur Sutra. Jakarta:

Departemen Pendidikan dan

Kebudayaan Republik Indonesia.

Atja. 1972.

Tjarita Purwaka Tjaruban

Nagari. Jakarata: Ikatan Karyawan

Museum.

1986.

Carita Purwaka Caruban Nagari;

Karya Sastra sebagai Sumber

Pengetahuan Sejarah. Bandung:

Proyek Pengembangan

Permuseuman Jawa Barat.

1988.

Menjelang Penetapan Hari Jadi

Pemerintahan Kabupaten Cirebon.

Cirebon: Pemerintah Kabupaten

Daerah Tingkat II Cirebon.

dan Edi Ekajati. 1989.

Pustaka Rajya- rajya I Bhumi

NusantaraI. I. Suntingan Naskah

dan Terjemahan. Bandung: Bagian

Proyek Penelitian dan Pengkajian

Kebudayaan Sunda.

Ekadjati, S. Edi. 1991.

Sejarah Perkembangan

Pemerintahan Provinsi Daerah

Tingkat I Jawa Barat. Bandung:

Pemerintah Provinsi Daerah

Tingkat I Jawa Barat.

1978.

Babad Cirebon Edisi Brandes

Tinjauan Sastra dan Sejarah.

Bandung: Fakultas Sastra,

Universitas Padjadjaran.

Hermana. 1994/1995.

Pola Kehidupan Santri di

Pesanttren Jagasatru Kotamadya

Cirebon. Bandung: Departemen

Pendidikan dan Kebudayaan,

Direktorat Jenderal Kebudayaan,

Balai Kajian Jarahnittra.
Lubis, Nina Herlina, et.al. 2003.

Sejarah Tatar Sunda. Jilid I.

Bandung: Pusat Penelitian

Kemasyarakatan dan Kebudayaan

Lembaga Penelitian Universitas

Padjadjaran dan Masyarakat

Sejarawan Indonesia Cabang Jawa

Barat.

Johan, Irma M. 1995/1996.

Penelitian Sejarah Kebudayaan

Cirebon dan Sekitarnya Antara

Abad XV-XIX: Tinjauan

Bibliografi. Makalah Diskusi

Cirebon Sebagai Bandar Jalur

Sutera. Jakarta: Departemen

Pendidikan dan Kebudayaan

Direktorat Sejarah dan Nilai

Tradisional, Proyek IDS.

Lasmiyati, 1995.

Sejarah Keraton Kasepuhan di Kotamadya Cirebon. Bandung: Departemen Pendidikan dan Kebudayaan, Direktorat Jenderal Kebudayaan, Balai Kajian Jarahnitra, Bandung.

Rafles, Thomas S., 1817.

The History of Java Vol. II. London.

Salana. 1978.

Sejarah Cirebon I (Stensilan).

Sudjana, T.D. 1995/1996,

Pelabuhan Cirebon Dahulu dan

Sekarang. Makalah Diskusi

Cirebon Sebagai Bandar Jalur

Sutera. Jakarta: Departemen

Pendidikan dan Kebudayaan,

Direktorat Sejarah dan Nilai

Tradisional, Proyek IDSN.

Sulendraningrat, P.S. 1968.

Nukilan Sedjarah Tjirebon Asli.

Tjetakan ke-2. Tjirebon: Pustaka.

1975.

Sejarah Cirebon dan Silsilah

Sunan Gunung Jati Maulana

Syarif Hidayatullah. Cirebon: 
Lembaga Kebudayaan Wilayah III Cirebon.

Sunardjo, RH Unang. Tanpa Tahun. Meninjau Sepintas Panggung Sejarah Pemerintah Kerajaan Cirebon 1479-1809. Cirebon.

Suyitno, Aang, et.al. 1991.

Bunga Rampai Jawa Barat.

Bandung: Yayasan Wahana Citra Nusantara.

Tedjasubrata. 1966.

Sedjarah Tjirebon Kawedar

Bahasa Daerah Tjirebon. Djilid II,
Bagian III- IV. Tjirebon: Tanpa Penerbit.

Tjandrasasmita, Uka. 1976.

Masuknya Islam ke Indonesia dan Tumbuhnya Kota-kota Pesisir Bercorak Islam. Jakarta: Bulletin Yaperna, Np. II tahun III, Pebruari 1976.

2009.

Arkeologi Islam Nusantara. Jakarta: Kepustakaan Populer Gramedia. 